Journal of Early Childhood Research, Volume 9 Issue 2 June 2011 pp. 125 - 136.

\title{
Trends in research about health in early childhood: Economics and equity, from micro-studies to big business
} Priscilla Alderson

Research about health is concerned with physical and mental wellbeing, illness and injury. It examines the causes and effects, treatment and prevention of problems, and the promotion of health. Directly or indirectly, health relates to almost every aspect of early childhood in two ways. Most aspects of life affect children's health and wellbeing, and their state of health can affect most other aspects of their daily life (Alderson, 2008).

Research about child health, illness and healthcare involves almost all research methods and disciplines, relates to numerous policies, services and professional practices, and produces thousands of reports every year. This paper aims to refer to the enormous range of research while tracing a few clear trends. From micro local studies to large macro international ones, I will look at their aims and purpose, methods and findings, and models or theories of childhood and child-adult relations. The paper reviews whether the research is mainly concerned with cost-effective economics or with equity and redistributing wealth and resources more equally among everyone. .

\section{Trends over four decades: economics and equity}

There are strong business trends in child health research. When I began doing research in the 1970s, the work was much less formal and expensive. It was easier for researchers to choose their own questions and topics, to raise funds and conduct fairly open-ended flexible studies. Conditions for research in universities are very different today, for some good reasons. Approval by a research ethics committee is now necessary. A wealth of computer resources informs and assists every stage of research. There are many more qualified and experienced researchers, and far more support from finance and human resources, IT and library, estates, public relations and administration departments.

However, in order to fund these resources, universities now aim to raise almost 200 per cent of the basic research costs. Many researchers are now advised or required to apply only to the few agencies, mainly government departments and research councils, which grant full economic costing, FEC. The charitable trusts, which tend to support more unusual and innovative studies, do not grant FEC. Much research has become big business in the scale of costs, which discourages small labour-intensive qualitative studies. Instead, in Britain, besides data collection by the Office of National Statistics, the National Health Service and related agencies, four main kinds of multi-million pound child health research are now promoted: clinical and social large trials and comparative studies; evaluations of services and their effects on children; systematic reviews; and longitudinal birth cohort studies.

The trend is towards quantitative, positivist and expensive research conducted by large hierarchical interdisciplinary teams. The data analysers may never meet the junior data collectors, let alone the children, who are mainly reduced to impersonal sets of numbers. The huge datasets may be sold on to other teams for further secondary analysis in order to make fuller use of the wealth of data, and to help to cover their high costs. 
This paper reviews how big business economics has pervaded not only the detailed methods and design of research but also the content, values, theories and approaches to childhood and health.

Economics and equity clearly go together. Economics research is vital to track the health and other material advantages or disadvantages for every child, if inequalities are to be tackled. However, vital differences between research guided primarily by economics or by equity will be reviewed. Beyond equality, equity respects equal rights and the reducing of all inequalities. The first section on micro-studies of early childhood, is followed by the international context, and then by larger scale health related research guided mainly by economics or by equity. The final section reviews the health of child health research.

\section{Micro-studies: equity and listening to young children}

From among many kinds of small studies with young children, this section reviews a few concerned with promoting equity. There is also concern for every child's rights: to basic goods and services such as health care; to the best attainable standard of health, United Nations Convention on the Rights of the Child (UNCRC, 1989: Article 24); to protection from abuse and neglect; and to freedom rights ranging from the right to life, to assurance to 'the child who is capable of forming his or her own views the right to express those freely in all matters affecting the child, the views of the child being given due weight in accordance with the age and maturity of the child' (UNCRC, 1989: Article 12). Listening to young children and learning from them is integral to providing them with adequate care.

Repeated Inquiries in Britain after young children die at home of abuse or neglect emphasise that adults must listen to children, but young children's views continue to be ignored. Karen Winter's research (2006) shows how out-dated child development theory still dominates social work training and practice, reinforcing mistaken ideas that young children are unable to form or express clear valid views, and the less said to them the better when they are removed from their parents' home. Winter's research also shows how competent children aged 4 to 7 years can be in talking about their feelings relating to their mental health, even if they have behaviour and communication problems, and feel anxious, powerless, mistrustful and let down by adults. They need very careful, patient, respectful listeners who help them to have some control over the interaction. The children decorated shoe boxes with craft materials, creating images of themselves outside the box, and inside they expressed their 'wishes and feelings' (the phrase from the 1989 Children Act that requires adults to consult children).

Useful methods for encouraging young children to trust and to talk include: sitting alongside them and concentrating on the craft work (instead of having potentially distracting or dominating eye contact); long pauses; children being able to make a comment like 'pass the glue' if they want to pause or delay answering a question; using craft work as well as talk and body language for communication; very gently repeating and affirming children's views without any judgment. 'Crystal' aged 5 years created a happy outside for her box but a sad inside, grieving for her baby sister who had died, and she was referred for bereavement counselling. 'Conor' aged 7 years explained how he hid his feelings. He asked Karen:

'On this bit of card er write me the word 'sad' and I'm gonna glue it down in my box so no-one can see it...One more not nice feeling and that is er what's that word with 'm' [pause] miserable. Could you do that on card for me? 
[Long pause while he makes fence of lollipop sticks and sellotape] ...I put a fence round my feelings; that's why I don't want no-one to see them' (Winter 2010).

Small studies - and many large ones - can seldom support solid generalisations, but they can refute misleading generalisations. Only a few expressive children are needed in research that disproves the fallacy, for example, that young children are neither willing nor able to talk about their deep feelings. Our research with children with type I diabetes found that from around 4 years of age some children can be trusted to understand their insulin treatment and complicated diet and to share in managing their daily health care (Alderson et al., 2006). (Children with type I are usually fit, slim and active, quite unlike cases of type II diabetes.)

Such examples of early competencies and interactions raise questions about when these capacities begin. Awareness and 'human' interactions, the microcommunication of nodding in time to speech and taking turns to vocalise, begin from birth (Field, 2007). Even premature babies show that they remember from before birth their parents' voices, and prefer them to other voices (Als, 1999). They quickly learn to distinguish between tender or painful touching, and flinch in anticipation of the routine painful treatment.

Babies interact with adults in ways that can inform and improve their care. For example, helping premature babies to find their preferred position reduces stress and helps babies to rest and sleep, and so to have more energy to feed, grow and resist infections. Babies 'form and express views' when they let adults know if they are distressed or need quiet or warmth. 'Baby-led' intensive care units are very different from the usual brightly lit noisy units (Als, 1999; Alderson et al., 2005). Babies respond, in the view of caring adults, with 'trust' and confidence to sensitive care and appear to invest meaning and to experience feelings, both emotions and sensations, in these interactions, in complex 'human' ways from the start. Full term babies, when 18 hours old, respond differently to a happy or abstracted or angry look from their carers (Murray and Andrews, 2000). Obviously, the youngest children cannot discuss or make complex decisions. But rather than developing though very different, seemingly unrelated ages/stages (like insects), children engage from birth along the lifelong continuum of human interactions and interdependencies that are integral to their health and wellbeing.

In their purpose, methods and findings and models of childhood and child-adult relations, small studies about competent young children aim for equity in these ways. They respect children as real, full, equal human beings and not simply future beings climbing slowly up from zero at birth towards adult perfection. They show that children have much to 'say' (through expressive body language, art, music, dance, play, talk and other media) and adults have much to learn. They consider that wellbeing and health matter as much in early childhood as in adulthood, not only for laying foundations of adult health, but because everyone's early childhood is precious too. And many of the studies challenge assumptions that the most intelligent, well-nurtured and protected children are the most mature morally and intellectually, that they are somehow superior and everyone should be more like them. Disadvantaged children who experience long term ill health or disability, poverty, family disruption, racism, war or migration, can show early maturity because of having to cope with adverse experiences that their more fortunate peers have not had to face. The next section moves from the smallest to the largest scale health research. 


\section{Child health: the international context}

Numbers The largest databases are governments', NGOs' and UN agencies' records of health and illness by country and by continent. Governments have undertaken to register every child's birth (UNCRC 1989; Article 7), partly in order to be able to assure basic protections and provision of services including healthcare to all their children. However, each year around half of all births are not registered, leaving statistics about the most disadvantaged children as incomplete estimates. There are about 128.9 million births annually, and half a million women die in childbirth, 1500 every day. The babies' health, if they survive, is precarious (UNICEF 2009). Every year, about 10 million children aged up to 5 years die, 20,000 children die each day, many from malaria, measles, diarrhoea or respiratory infections, which are easily prevented and cured in the wealthier minority world countries. With growing numbers of old and very old people, falling birth rates and fewer children in richer countries, disproportionate numbers of young children live in the majority world of 87 per cent of the world's people, and in absolute poverty.

Cities Today, more people in the world live in cities than elsewhere. There are 200,000 extensive slums, homes to over one billion people (Davis 2006; Khan 2009); 1.1 billion people lack clean safe water, and 2.4 billion lack sanitation systems. Electricity is another usually missing service. Slum lords use state and unofficial police to manage high levels of crime and violence. By 2000, over three quarters of the people in Delhi India were living in slums and not in the planned and serviced city areas. Since 2000, over half a million slum-dwellers have been evicted, with routine bulldozing and demolition of slums (Batra, 2009).

Many people choose to go to cities to work or study, to join relatives and friends, to escape from poverty or violence. However, many are displaced from their land by armed conflict, or by theft through planning policies to replace villages with agrobusinesses, or with flooding for huge dams, or to sell or lease the land to agents from wealthier countries who grow food, flowers and biofuels for export (Vidal, 2010). Modern agriculture increases pollution and drought, and drains water tables. The capital of Yemen, Sana'a, 'is set to become the first city in the world to die of thirst' (Macleod et al., 2010); there are fewer than 200 cubic meters of water per person per year. The international water poverty line is 1,000 cubic metres. A further problem is that the United Nations (2009) estimated that in the year 2007-8, over 211 million people were very severely affected by the effects of climate change, by droughts or floods, which drive survivors into cities and refugee camps.

Babies and young children are the group most immediately and fatally affected by all the above problems: by heat and dehydration, infection and malnutrition; by inadequate care and housing and play spaces; by the risks of being lost, abandoned or kidnapped during dangerous events; and by adults' helpless despair, anger, violence, ignorance or indifference (UN, 2006). In the aims and purpose, methods and findings, and concerns with both economics and equity, international health research can be immensely valuable, although children are often side-lined.

Rights and needs International health research crucially contributes to policymaking, and to informing public opinion and support for fair trade and aid. Yet world poverty and inequality continue to grow. The Bangladeshi head of Amnesty International, Irene Khan, contends that economic growth, secure markets and 
greater opportunities can help people living in poverty. But they also need power, and recognition of their political, social and economic human rights. Her book ends:
"'All human beings are born free and equal, in dignity and in rights" (UDHR 1948: Article 1). The struggle to end poverty...is this generation's great struggle. We will win it if we put freedom, justice and equality at its core' (Khan, 2009: 229).

Historic human rights founded on equality for all are very detailed and carefully worded, all inter-related and mutually reinforcing, and enshrined in strong international treaties with named accountable agents (for example, CEDAW 1979, UNCRCR 1989, stemming from UDHR 1948). Unfortunately, attention has shifted from human rights towards the much vaguer, more selective and arbitrary Millennium Development Goals (MDGs) and Capabilities Theory, promoted by the economists Jeffrey Sachs (2005) and Amartya Sen (1999).

Big business research and policy Although economics-led international research about child health in its aims and purpose may be compassionate, it is mainly utilitarian. In many positive ways, the aims are to promote trade and wealth, and efficient non-corrupt national and local management of money, resources and services. The methods and findings primarily concern need, and ways to provide and evaluate responses to need. The implicit models of childhood and child-adult relations, if children are considered at all, are of needy children and providing adults, children in danger and rescuing adults, children as functioning or malfunctioning machines supervised by technician-practitioners, children as investments for the future, who are learning to be future economic agents able to repay their ageing parents' care. The models tend to disapprove of children's paid work (often essential for their survival) and to ignore children's present agency and views, contributions and rights, and even their existence. Even Irene Khan's splendid emancipatory book, for example, claims: 'women make up the bulk of the population of slums' (2009:149). Instead, women are about one quarter and children and young people are over one half of slum-dwellers.

Much international research, linked to MDGs and Capability, and including large drug trials with majority world children, is dominated by economists and statisticians and conducted on the scale of big business in its aims, topics, values, methods, findings, conclusions and policy recommendations.

Conventional economists see the present world order of industrial growth as the essential and only hope for future world prosperity (Hamilton, 2003), They ignore how industrial capitalism is multiplying many of the world's problems, and especially the poverty and ill health of majority world children. Present forms of capitalism do so by: procuring majority world resources at unfairly low prices and discounting pollution and dwindling resources (Plumwood, 2002; Stephens, 2006; Monbiot, 2007; Kempf, 2008; Miller, 2009); driving down taxes, welfare support and wages, privatising services and driving up private profits, and the cost of living, and therefore the numbers of people living in poverty (Klein, 2007; Brady 2009; Jackson, 2009); then punishing the poor for their protests by boosting the billions of dollars spent on police and prison services (Wacquant, 2009). The cycles lead to ever higher consumption, waste and carbon emissions, with resulting climate and weather changes that damage land, harvests, food chains, oceans and fresh water supplies, thereby fuelling disputes and armed conflict, and subsequent forced migrations. 
There is space here only to question the present world order, not to review new approaches in 'green economics' developed by the above authors, except to say that their work is based on the aims and purpose, methods and findings of equity and respect for the health of all people and the planet. It is, however, disappointing that this promising new work is generally so adult-centric, leaving vital gaps for childhood researchers to work on.

\section{Economics-led research about child health in Britain}

Poverty also undermines the health of many children in the richer minority world. A survey of the 21 richest countries (UNICEF, 2007) found that the UK and the US had the highest scores for child poverty and for inequality between the highest and lowest incomes. Among a total of 11.5 million children in Britian, 4 million live in poverty (DWP, 2009). The richest 10 per cent of people in Britain are 100 times better off than the poorest 10 per cent. The richest one per cent is over 300 times wealthier (NEP, 2010:7), and health is closely tied to income level.

Since 2000 , rising inequality, the financial credit crunch, and poverty data have refuted four government assumptions about 'eliminating child poverty'.

First, the 'trickle down' of wealth theory assumes that when the rich get richer the poor benefit too, whereas instead inequality increases.

Second, child poverty is not necessarily reduced when both parents do paid work. Instead, low wages now mean that most children living in poverty have working parents (DWP, 2009).

Third, education is not necessarily the route out of poverty and better educated working class people still have lower prospects than middle class people (NRP, 2010: 33-4). Qualifications are important but insufficient with today's limited, often low paid, insecure employment prospects. And are the millions of low paid workers to be thanked for providing essential services, and paid more to reduce poverty rates, or else to be blamed for their low qualifications as if these are entirely personal failings and nothing to do with social differences?

Fourth, the government's insistence on 'equality of opportunity' (instead of also on more equal supports and outcomes) is not working 'when there are such wide differences between the resources which people and their families have to help them fulfil their diverse potentials' (NEP 2010:1).

Serious social research examines tensions between structure and agency, unequal resources and opportunities. Equal opportunities and capabilities approaches respect individuals' initiative, courage and enterprise, but risk discounting severe disadvantages, such as ill health or disability, and then risk blaming individuals. Debates about these four assumptions tend to ignore children, although they are so closely affected by them.

Multi-million pound research on child health (apart from medical drug trials) is mainly funded by government-related agencies, and they tend increasingly to set the topics and questions for collecting 'facts' and statistics about childhood problems, through the following methods.

Systematic reviews summarise dozens or hundreds of related research reports to discover the major agreed findings (see, for example.www.ioe.ac.uk/ssru/eppi/). Depressingly, very few reports usually meet the reviewers' high standards, and even fewer give convincing evidence of effective interventions that can actually improve lives. The benefits of the reviews are that findings from many small and large studies can be all drawn together. These are either validated and gain power, or else are 
shown to be flawed. Potentially there is then stronger evidence to support policy decisions about which practices to promote, or to be cautious about, or to withdraw if reviews show they are useless or harmful. Among the disadvantages of reviews are that they tend to concentrate negatively on deficits and problems in childhood. Reviews are trapped into the older questions, methods and agenda of already published research, such as ignoring children's own views; reviewers can only note the gaps but not fill them in. Reviews tend to present data as if they are straight facts, without attending to the complicated contexts and co-constructions of research knowledge.

Evaluations of child health and welfare services can usefully assist everyone to see which services work well - or not, so that service providers can be held to account. Providers may be praised or criticised, and their contracts may be renewed or ended, depending on the results. Disadvantages of evaluations can include: poorly designed research; inconclusive and biased evaluations; premature evaluations before the outcomes can emerge; policy makers ignoring or dismissing sound results, or skewing the reports to fit their policy claims; service providers being funded to evaluate their own services; and vulnerable service-users being afraid to speak honestly. For example, parents who have to attend classes on how to deal with their children's mental health problems may not dare to describe their problems fully, or criticise the classes, or say they have not benefitted, in case their child might be taken away from them.

Longitudinal research includes Birth Cohorts, and this section reviews a report about the first nine months in the lives of 18,819 babies born in 2000 (Dex and Joshi, 2005). Families from disadvantaged areas and ethnic minority are deliberately over represented. Data collected during interviews and self-completion questionnaires are meticulously presented in many tables and figures. The questions cover pregnancy, birth and early development; household members, other family and friends; child care; babies' temperament and behaviour; parents' age, mental health, depression, weight, smoking and drinking habits; parents' attitudes and relationships, employment and education; housing and local areas; household income and resources. The study aims to draw comparisons with earlier cohorts (from 1958 and 1970 ) in order to see how new policies and frameworks are changing present life courses.

Society is seen as willing to invest in cohort child studies because, economically: society contributes to family budgets; children are an investment for the future labour force (to produce wealth and tomorrow's pensions); children should not have to suffer the full extent of their parents' low incomes. Dex and Joshi (2005: 237-8) say that the 'large cost' of cohort studies is justified when studies:

- Allow us to come as close as possible to identifying causal mechanisms in individual's behaviour;

- Conduct 'natural' experiments by recording control and comparison groups that happen to be exposed to different events so identifying more of the causal mechanism in, for example, social problems;

- Chart social changes and disentangle reasons for them within and between different cohorts;

- Show how histories of health, wealth, education, family and employment vary and affect later achievements. 
Purists would say that only randomised controlled trials (RCTs) can approach these aims, and neither the cohort's large weighted samples from much larger populations, nor their statistical analysis, can reveal causes. Even RCTs can only discover associations, not prove cause or effect, although Dex and Joshi loosely conflate 'causal mechanisms', 'causes', 'quasi-causes' and 'associations'. They briefly refer to social and human capital and to capabilities, but use these concepts to describe their data, not for analysis. To analyse social causes involves searching for underlying structures and forces like ocean currents, which shape social relations (Bhaskar, 2008), whereas the cohort reports tend to concentrate on rearranging surface patterns and associations as if they are causes.

Economics is central to the research design and analysis in the concern with: government policies about child poverty and initiatives to encourage parental employment; costs and benefits of new government frameworks for child care and health; efforts to prevent and reduce costly ill health and obesity (2005: 1). Babies are presented rather as cost units than persons. Referred to as 'it', they are often erased, as when single parents who live with their babies are called 'lone' parents, and mothers were asked 'whether no one [sic], the baby's father, or [either grandmother] was present during the birth'. The research design does not convey much understanding or liking of babies. Somewhat negative terms are given to describe maternal feelings: annoyance; thinking about the baby when apart; feeling sad when leave baby; extent of impatience with baby; resent giving up things because of baby (2005: 201). The authors wonder if Parliament 'has gone too far [during 2004, in] voting on whether to allow families [meaning parents] to smack their children' (2005: 2). Would they be so nonchalant about women being hit? Housework too, and by implication the work-object babies, are analysed mainly in cost terms, of time, fair division between partners, something to be fitted efficiently around paid work.

The questions seem to allow little scope for parents to say what they enjoy or find rewarding and fulfilling. And if adults do not enjoy home and family life, what is the point of all their working and earning? There is an implied bleak meaninglessness to life. The survey looks at cost but not at value, or at parents sharing happiness and the good life with their babies. 'Communication [is] for language development' (2005: 250) and 'cuddling is important', but it is implied 'important' means promoting healthy future development. 'Babyhood' remains untheorised and implicitly negative, a prelude rather than a valued life-stage, with the emphasis on the future. 'It is a long way ahead before we will begin to see the effects of early experiences on their cohort adults' lives' (2005: 238). The authors support the four contested government assumptions about reducing child poverty listed earlier in this section.

From research to policy and practice How relevant will the babyhood data be after 20 or 30 years of likely great changes in both social structures and also among all the 18,819 unpredictable children? Analysts of older cohorts connect adult performance back to babyhood data. For example, in the 1970 birth cohort, many disadvantaged babies aged 22 months were already achieving less than their peers, a pattern that continued for many of them for the next 30 years. Feinstein (2003: 24) warned:

'These differences are not set in stone, far from it, but may be hard to break later. This means that policies to reduce inequality and increase average levels of performance that come into play after children have reached primary school age may struggle to achieve the success that one may wish for 
them.'

Feinstein advised that preschool staff are so important that their pay and conditions should be improved, to increase recruitment and retention of staff and continuity and security for children. Politicians responded in two negative ways - a warning for all childhood researchers. They seemed to take the data far too seriously, as if behaviour at 22 months determines the whole life course. Yet even so, they did not raise pre-school staff salaries.

Politicians' responses illustrate risks that cohort reports may pose to children's wellbeing. The risks include: overlooking the value and hopes and openings of their long varied childhoods; advancing gloomy, self-fulfilling, fatalistic prophecies; panicking and pressurising very young children to achieve early; dismissing their potential (and that of their teenage mothers) far too soon; ignoring how either negative or positive labels and expectations can affect teachers' attitudes and their powerful influences on each child's wellbeing, learning and future (Gillborn, 2008). This last point emphasises, first, that children's successes or failures, health and wellbeing, are not simply fixed facts. Instead they are in flux, and are partly coconstructed by children's and adults' beliefs and interacting behaviours. And second, to over-connect adult life back to omens at 22 months risks reducing life down to the personal, and to beliefs that extra educational exercises will assure success. This would ignore economics, politics, employment policies and many other vital social matters. It would transfer too much blame and responsibility on to unsuccessful, disadvantaged individuals, and away from policy makers and markets.

Although large reviews, evaluations and cohorts, in their purposes, methods and findings, aim to promote child welfare and equality, they tend to be influenced by economic theories and policies, which are not achieving equity.

\section{Equity led child health research in England}

CRAE, the Children's Rights Alliance for England, provides examples of research led by human rights and equity. CRAE is run for and with children and young people working with many specialist organisations. CRAE's detailed annual reports on The State of England's Children analyse how the government is implementing all the UNCRC Articles, which it undertook to do when ratifying the UNCRC in 1991.CRAE's reports collate the latest statistics on many aspects of children's lives, with reviews of government policies and action - or inaction, critical comments from leading authorities, and recommendations. For example, England has very poor rates of breast feeding.

'Babies who are not breastfed are five times more likely to be admitted to hospital with gastroenteritis and they are more at risk of becoming...obese in later childhood. Increasing breastfeeding can help to reduce inequalities in health outcomes, as relatively disadvantaged groups tend to breastfeed less' (CRAE, 2009).

CRAE lists recent efforts and the latest evidence and also, unlike most of the above large scale projects, points to necessary political action.

'The aim of the Code of Marketing of Breastfeeding Substitutes is to contribute to the provision of safe and adequate nutrition for infants by ensuring the proper use of breast milk substitutes. The Government has 
continually failed to fully implement the Code' on restricting baby milk companies' promotions (CRAE, 2009).

CRAE (2009 chapter 6 on health) also reports that standing out among disadvantaged groups are Traveller children, with exceptionally poor health and education records. These numerous childhood difficulties have seen decades of government initiatives, education, expensive 'inclusion' training courses for professionals, and nicely written, lavishly designed research reports on how to improve services, as if parents and professionals together can and should solve all the problems. Instead of tinkering with inequalities, mainly by rolling back direct state support and rolling forward surveillance (including research) and control of the family (Scambler, 2001), the overwhelming evidence is to reduce inequalities is the most effective way to promote child health and wellbeing (Wilkinson and Pickett, 2009).

CRAE advocates reintroducing the legal duty on local authorities to provide traveller sites, a duty removed by the Criminal Justice and Public Order Act 1994. This would help Traveller families to live long enough on sites with water, sewage and electricity services to enable children to settle into preschool and school. The cost of reopening the closed sites would be lower than the potential lifelong costs of presently disrupted childhoods, with frequent evictions by the police.

The government aims to avoid imposing restrictions on industry, including baby milk companies, and to avoid annoying householder voters who live near Traveller sites. So instead of direct action, it funds displacement activities including large and small scale research about Travellers' problems and failings. CRAE illustrates how independently funded research centres, in their aims, methods, findings and respectful working with and for children, can promote child health and equity more decisively than large university centres may do.

\section{The health of child health research}

Some areas of child health research are in a parlous state, with a tendency to research children as if they live in an unreal political and economic vacuum called childhood. There is then a danger of ignoring underlying economic pressures on the research aims, design, methods and findings.

The steep rise in the cost of university research, while bringing valuable supports, has trapped researchers into unhealthy dependence on large funders and their agendas. Researchers are further trapped when they adopt big business models in: the size and terms of the grants; the purpose of endorsing government economic policies rather than critically examining them; the documenting of disadvantaged families' supposed inadequacies; the hierarchies of research directors with low-paid assistants doing quite menial technical tasks with large databases; the distancing of child subjects reduced and silenced into rows of numbers; market research kinds of limited reply options offered to participants, which distort reports of their views and experiences; most of all, the reduction of children into units of cost analysis. This involves calculating childhood relationships and experiences as investments.

Researchers also estimate the present and potential costs if future adults fail to become high-earners, but instead 'consume' health, psychiatric, prison and other state services, in 'not fulfilling their potential' (HM Treasury et al., 2003).

Big business approaches to research deal in:

superficial findings that ignore complexity and context;

data presented as self-evident 'evidence';

associations being offered as causes; 
allusion to 'social capital' as if this is theoretical analysis.

There are also positivist methods, which work well in medical trials which examine how a patient with cancer reacts to a drug, but less well in everyday social life.

Among the effects are that:

the child and family are treated as quasi-patients;

they are thereby pathologised as the site or cause of the problems;

social and economic problems are removed from the political domain, and over-

attributed to the personal domain;

it is implied that health is almost a (market) product or commodity 'delivered' to the child, or produced by two earning parents.

Instead, health is a living state, partly constructed and sustained by children's and adults' interdependent interactions within political and economic contexts.

This paper has reviewed the importance of mutual adult-child equity, respect and learning in these interactions, and the dangers when these are missing. When the values are so vital in the lives of the children we research, can we promote these values unless they pervade our health research aims, purpose, methods, findings, recommendations and theories of childhood?

\section{References}

Alderson, P. (2008) Young Children's Rights. London: Jessica Kingsley.

Alderson, P., Hawthorne, J. and Killen, M. (2005) 'The Participation Rights of

Premature Babies', International Journal of Children's Rights 13: 31-50.

Alderson, P., Sutcliffe, K. and Curtis, K. (2006) 'Children as Partners with Adults in their Medical Care', Archives of Disease in Childhood, 91: 3000-3.

Als, H. (1999) 'Reading the Premature Infant', In Edward Goldson (ed)

Developmental Interventions in the Neonatal Intensive Care Nursery, pages 18-85.

New York: Oxford University Press.

Batra, L. (2009) 'Class against class: the neoliberal resturcuturing of Delhi', Centre for the Study og Democracy Bulletin, 16. 1-2: 1-2, 28.

Bhaskar, R. (2008) A Realist Theory of Science. Abingdon: Routledge.

Brady, D. (2009) Rich Democracies: Poor People. Oxford: Oxford University Press. CEDAW. (1979) Convention on the Elimination of all Forms of Discrimination against Women. New York: UN.

CRAE. (2009) State of England's Children. London: CRAE.

Davis, M. (2006) Planet of Slums, London: Verso.

Department for Work and Pensions. (2009) Households Below Average Income. London: DWP.

Dex, S. and Joshi, H. (2005) Children of the 21st Century: From birth to nine months. Bristol: Policy.

Dunn, J. (2004) Children's Friendships: The Beginnings of Intimacy. Oxford: Blackwell.

Field, T. (2007) The Amazing Infant. Oxford; Blackwell.

Feinstein, L. (2003) 'Very early cognitive devekopment', CentrePiece, 24-30,

Summer.

Gillborn, D. (2008) Racism and Education: Coincidence or Conspiracy? Abingdon:

Routledge.

Hamilton, C. (2003) Growth Fetish. London: Pluto Press.

HM Treasury et al., (2003) Every Child Matters. London: Stationery Office. InterGovernmental Panel on Climate Change. (2007) Fourth Report on Global Warming. IPCC. 
Jackson, T. (2009) Prosperity Without Growth. London: Earthscan.

Kempf, H. (2008) How the Rich are destroying the Poor. Dartington: Green Books. Khan, I. (2009) The Unheard Truth: Poverty and Human Rights. New York: W W Norton.

Klein, N. (2007) The Shock Doctrine. London: Penguin.

MacLeod, M., Dahr, W. and Vidal, J. (2010) 'Once it was paradise: now Yemen runs dry', Weekly Guardian, 5-11 March: 1.

Martin, G. and Clark, R. (1982) Distressed crying in neonates: species and peer specificity. Developmental Psychology, 18: 3-9.

Meltzoff. A. (2004) 'The case for a developmental cognitive science: theories of people and things'. In G. Bremner and A. Slater (eds) Theories of Infant

Development. Pages 145-73, Oxford: Blackwell.

Miller, N. (2002) Environmental Politics. Abingdon: Routledge.

Monbiot, G. (2007) Heat. London: Penguin.

Murray, L. and Andrews, H. (2000) The Social Baby. Richmond: The Children's

Project.

NEP - National Equality Panel (2010) An Anatomy of Economic Inequality in the UK: Summary. London: Government Equalities Office.

Nussbaum, M. (2000) Women and Human Development: the Capabilities Approach. Cambridge: Cambridge University Press.

Plumwood, V. (2002) Environmental Culture. Abingdon: Routledge.

Sachs, J. (2005) The End of Poverty. London: Penguin.

Scambler, G. (ed) (2001) Habermas, Critical Theory and Health. London: Routledge.

Sen, A. (1999) Development as Freedom. Oxford: Oxford University Press.

United Nations (2009) World Population Report. New York: UN.

Stephens, P. (ed) (2006) Contemporary Environmental Politics. Abingdon:

Routledge.

Stern, N. (2006) Report on the Economics of Climate Change. London: HM

Treasury.

UDHR. (1948) Universal Declaration of Human Rights. New York; UN.

United Nations. (1989) Convention on the Rights of the Child. New York: UN.

United Nations (2006) UN Secretary General's Study on Violence against Children.

New York: UN.

United Nations. (2009) World Population Report. New York: UN.

UNICEF (2007) An Overview of Child Well-being in Rich Countries. Geneva:

UNICEF.

UNICEF (2009) State of the World's Children. Geneva: UNICEF.

Vidal, J. (2010) 'How food and water are driving a 21st-century African land grab',

Sunday Observer, page 18.

Wacquant, L. (2009) Punishing the Poor. London: Duke University Press.

Wilkinson, R. and Pickett, K. (2009) The Spirit Level. London: Penguin.

Winter, K (2006) The participation of 'looked-after' children in their health care: a

critical review of the research, International Journal of Children's Rights, 14,1:77-97.

Winter, K. (2010) 'Ascertaining the perspectives of young children in care: a case study using reality boxes', In press.

Woodiwis, A. (2005) Human Rights. London: Routledge. 